\title{
Can Fear of Movement, Depression and Functional Performance be a Predictor of Physical Activity Level in Patients With Knee Osteoarthritis?
}

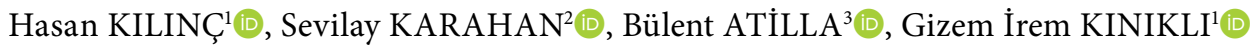 \\ ${ }^{1}$ Department of Physiotherapy and Rehabilitation, Hacettepe University Faculty of Health Sciences, Ankara, Turkey \\ ${ }^{2}$ Department of Biostatistics, Hacettepe University Faculty of Medicine, Ankara, Turkey \\ ${ }^{3}$ Department of Orthopaedics and Traumatology, Hacettepe University Faculty of Medicine, Ankara, Turkey
}

\begin{abstract}
Objectives: This study aims to explore whether fear of movement, depression and functional performance are predictors of physical activity levels in patients with knee osteoarthritis (OA).

Patients and methods: A total of 200 patients ( 80 males, 120 females; mean age $53.23 \pm 5.99$ years; range, 40 to 65 years) with knee OA participated in this cross-sectional, correlational-design study. Oxford Knee Score (OKS) was used to evaluate physical function and pain through patient perspective. Six-Minute Walk Test (6-MWT) was used to evaluate functional performance. International Physical Activity Questionnaire-Short Form (IPAQ-SF) was used to assess subjective physical activity level. A 17-item of the self-reported Tampa Scale for Kinesiophobia (TSK) questionnaire was used to determine the fear of movement level. Beck Depression Inventory (BDI) was used as a self-reported measure for depression level. Spearman correlation analysis and the linear regression model with $\mathrm{R}$-square $\left(\mathrm{R}^{2}\right)$ were used to correlate and explain the total variance.

Results: International Physical Activity Questionnaire-Short Form was significantly correlated to OKS ( $r=-0.550), 6-M W T(r=-0.561)$, TSK ( $r=-0.693)$ and BDI $(r=-0.429)$ in patients with OA $(p<0.001)$. Linear regression analysis revealed that OKS, $6-$ MWT test, TSK and BDI were independently associated with IPAQ-SF in predicting physical activity level in patients with knee $O A\left(p \leq 0.001 ; R^{2}=0.621\right)$.

Conclusion: This study increases the understanding of the predictors of physical activity level related to fear of movement, depression and functional performance in patients with knee OA. Improving physical activity levels in OA population is necessary to implement early treatment strategies before the disease progresses and more costly solutions are needed.

Keywords: Depression; function; knee; osteoarthritis.
\end{abstract}

Physical activity is defined as body movements resulting from the contraction of skeletal muscles and resulting in energy expenditure. This definition covers all kinds of human movements, from exercise and racing sports to hobbies and daily life activities. ${ }^{1}$ Occupational activities are some of the varieties of physical activity (e.g. self-care, general cleaning), transportation (e.g. walking, cycling) and leisure activities (e.g. swimming, dancing).
Activities that do not significantly increase energy expenditure are called sedentary behaviors such as sleeping, sitting, reading, watching television and using computers.

Osteoarthritis (OA) is the most common type of degenerative arthritis, most common in knee and hip joints. However, when considering the etiology of OA, physical activity can mechanically increase joint cartilage and degeneration in bones.

Received: September 03, 2018 Accepted: November 08, 2018 Published online: November 30, 2018

Correspondence: Gizem İrem Kınıklı. Hacettepe Üniversitesi Sağlık Bilimleri Fakültesi, Fizyoterapi ve Rehabilitasyon Anabilim Dalı, 06100 Altındağ, Ankara, Turkey. Tel: +90 312 - 3052525 / 208 e-mail: cguvendik@hotmail.com

\section{Citation:}

Kılınç H, Karahan S, Atilla B, Kınıklı Gi. Can fear of movement, depression and functional performance be a predictor of physical activity level in patients with knee osteoarthritis? Arch Rheumatol 2019;34(3):274-280. 
Because of this reason, it cannot be said that physical activity is a cause or an outcome for OA.

Fear of movement due to pain in patients with knee $\mathrm{OA}$ is related to loss of function and physical performance, too. ${ }^{2,3}$ The aim of physiotherapy and rehabilitation applications in the treatment of knee $\mathrm{OA}$ is to control the pain, to maintain and improve the function with muscle strengthening exercises, to protect the joint and to increase the quality of life by keeping the damage to a minimum level. ${ }^{4,5}$ Regular mild to moderate physical activity is recommended because of its beneficial effects such as developing cardiovascular fitness and reducing the risk of diabetes and obesity. ${ }^{6}$ Integration of exercise and physical activity, particularly for individuals with knee $\mathrm{OA}$, is advised including moderate physical activity ( $\geq 3$ metabolic equivalent of task (MET) for at least 30 minutes at least three days a week. According to the Chronic Diseases Risk Factor Study, $87 \%$ of females and $77 \%$ of males do not have sufficient physical activity. ${ }^{7}$ It is generally suggested to avoid activities such as climbing stairs, which will often load string, and to walk for a long time particularly for those with knee OA. However, it is noteworthy that the level of physical activity was rarely assessed in studies conducted on individuals with OA. It has been stated that the methods that directly measure physical activity, such as accelerometer, are expensive and survey methods are not used frequently in individuals with OA. ${ }^{8-10}$ Although various clinical trials have used subjective methods to describe physical activity in knee OA, objective measures of physical activity are still necessary to determine the predictors, duration and intensity of physical activity levels in this population. ${ }^{11}$

Currently, studies examining the association of fear of movement, depression and physical performance on physical activity levels in patients with knee OA are not consistent and limited by small sample size. In addition, potential predictors of physical activity levels in knee OA population have not yet been explored. Therefore, in this study, we aimed to explore whether fear of movement, depression and functional performance are predictors of physical activity levels in patients with knee OA.

\section{PATIENTS AND METHODS}

This study was conducted on 200 patients (80 males, 120 females; mean age 53.23 \pm 5.99 years; range, 40 to 65 years) diagnosed as knee OA according to American College of Rheumatology Association criteria between February 2017 and November 2017 in Hacettepe University Hospital, Department of Orthopedics and Traumatology Clinic. The study protocol was approved by the Hacettepe University Ethics Committee for Non-Interventional Clinical Investigations (GO 17/85-05). A written informed consent was obtained from each patient. The study was conducted in accordance with the principles of the Declaration of Helsinki.

Kellgren-Lawrence classification system was utilized for radiological grading of the patients via standard anteroposterior radiograms of the weight-bearing knee. Radiological grading of knee $\mathrm{OA}$ was performed by the same surgeon for all patients and those patients having Grade II-IV knee OA were enrolled. Patients who previously had knee surgery, those with infection in areas near the knee joint, with metal implants, serious hearing loss or impaired vision, individuals with communication problems and uncontrolled high blood pressure were excluded.

Participants' physical and sociodemographic characteristics, and functional evaluations were completed by a physical therapist and consisted of measuring height, weight, body mass index, dominant side lower extremity, selfperceived functional ability, and objective physical performance.

The Oxford Knee Score (OKS) is a valid and reliable questionnaire that assesses pain and function from the perspective of patients. ${ }^{12,13}$ It is scored between 0 (no) and 4 (severe) in the Likert system (0-48). In OKS, which consists of 12 questions, questions $2,3,7,11$, and 12 evaluate the functional status, while questions $1,4,5,6,8,9,10$ assess pain-related condition. Higher scores indicate pain and malfunction of functional status.

The Six-Minute Walk Test (6-MWT) has good reliability to measure functional performance among people with knee OA. ${ }^{14}$ Patients were instructed to walk at their own pace to cover maximum distance (meter) in six minutes and 
were not provided any feedback during the test. The test was repeated three times and averaged.

The Turkish version of International Physical Activity Questionnaire-Short Form (IPAQ-SF) was used to determine the subjective physical activity level of the patients. ${ }^{15,16}$ The IPAQ is a scale used to measure physical activity level of individuals, which is expressed in units of MET, by evaluating the frequency and duration of physical activities performed within one week. MET score for walking is calculated by multiplying the time spent for walking per day by the number of walking days per week and 3.3 METs. MET score for moderate activity is calculated by multiplying the time spent for moderate activity per day by the number of moderate activity days per week and 4 METs. MET score for vigorous activity is calculated by multiplying the time spent for vigorous activity per day by the number of vigorous activity days per week and 8 METs. Total physical activity score is obtained by summing these three scores (MET-minute/week). Scores are presented as MET-minutes per week. The IPAQ-SF classifies populations into low (scores of $<599$ ), moderate (scores between 600 and 2,999) or high physical activity level (scores over 3,000) groups.

A 17-item Turkish version of the self-reported Tampa Scale for Kinesiophobia (TSK) questionnaire was used to assess the fear of movement. ${ }^{17}$ Each item was scored using a 4 -point Likert scale ranging from 1 to 4 (1=strongly disagree and $4=$ strongly agree). The total score was calculated by adding the scores of the individual items (range, 17-68) with higher scores indicating a greater degree of kinesiophobia. ${ }^{18}$

A 21-item self-report rating inventory, Beck Depression Inventory (BDI), was used to detect depression. BDI measures characteristic attitudes and symptoms of depression. Higher total score indicates more severe depressive symptoms. Index

Table 1a. Descriptive statistics for demographic factors $(n=200)$

\begin{tabular}{lcc}
\hline Categorical variables & $\mathrm{n}$ & Cumulative (\%) \\
\hline Gender & & \\
$\quad$ Female & 120 & 60 \\
$\quad$ Male & 80 & 40 \\
Radiographic severity & & \\
$\quad$ Grade II & 108 & 54 \\
$\quad$ Grade III & 62 & 31 \\
Grade IV & 30 & 15 \\
IPAQ-SF categories & & \\
$\quad$ Low physical activity level (0-599) & 12 & 6.0 \\
Moderate physical activity level (600-2,999) & 156 & 16.0 \\
$\quad$ High physical activity level (>3,000) & 32 & \\
\hline IPAQ-SF: International Physical Activity Questionnaire-Short Form. & & \\
\hline
\end{tabular}

Table 1b. Descriptive statistics for main outcome measurements $(n=200)$

\begin{tabular}{lcc}
\hline & Mean $\pm \mathrm{SD}$ & Range \\
\hline Age (year) & $53.2 \pm 6.0$ & $40-65$ \\
Body mass index $\left(\mathrm{kg} / \mathrm{m}^{2}\right)$ & $27.2 \pm 4.1$ & $25-28$ \\
Disease duration (year) & $8.5 \pm 3.9$ & $3-14$ \\
Oxford Knee Score (0-48) & $24.1 \pm 8.1$ & $0-44$ \\
Six-Minute Walk Test (meter) & $532.7 \pm 101.0$ & $254-742$ \\
Tampa Scale for Kinesiophobia (17-68) & $31.8 \pm 10.4$ & $10-63$ \\
Beck Depression Inventory (0-63) & $11.6 \pm 7.2$ & $2-48$ \\
IPAQ-SF (MET-minutes/week) & $1,946.99 \pm 894.7$ & $270-3,900$ \\
\hline SD: Standard deviation; IPAQ-SF: International Physical Activity Questionnaire-Short Form; MET: Metabolic \\
equivalent of task.
\end{tabular}




\begin{tabular}{|lcc|}
\hline \multicolumn{2}{l}{ Table 2. Bivariate correlations between IPAQ-SF and OKS, 6-MWT, TSK, BDI } \\
outcomes & $\mathrm{r}$ & $\mathrm{p}$ \\
\hline & $-.550^{*}$ & 0.000 \\
\hline Oxford Knee Score & $-.561^{*}$ & 0.000 \\
Six-Minute Walk Test & $-.693^{*}$ & 0.000 \\
Tampa Scale for Kinesiophobia & $-.429^{*}$ & 0.000 \\
Beck Depression Inventory & & \\
\hline IPAQ-SF: International Physical Activity Questionnaire-Short Form; OKS: Oxford Knee Score; 6-MWT: \\
$\begin{array}{l}\text { Six-Minute Walk Test; TSK: Tampa Scale for Kinesiophobia; BDI: Beck Depression Inventory outcomes; } \\
\text { r: Spearman rank correlation coefficient; " p<0.001. }\end{array}$ \\
\hline
\end{tabular}

\begin{tabular}{|c|c|c|c|c|}
\hline Model & Variables & $\mathrm{R}^{2}$ & $\mathrm{~F}$ & Significance \\
\hline \multirow{4}{*}{1} & Oxford Knee Score & \multirow{4}{*}{0.621} & \multirow{4}{*}{79.761} & \multirow{4}{*}{$0.000^{*}$} \\
\hline & 6-MWT: Six-Minute Walk Test & & & \\
\hline & Tampa Scale for Kinesiophobia & & & \\
\hline & Beck Depression Inventory & & & \\
\hline
\end{tabular}

score of $\leq 9$ is considered to be within normal range, a score of $10-15$ shows minimal depressive symptomatology, a score of $16-31$ points toward mild depression, a score of $32-47$ is in favor of moderate depression, and a score of $>47$ indicates severe depression. The maximum total score is 63, whereas the minimum is $0 . \cdot^{19,20}$

\section{Statistical analysis}

Data analysis was conducted in three steps using IBM SPSS version 22.0 software (IBM Corp., Armonk, NY, USA). First, Spearman rank correlation analyses were conducted to determine the relationship between physical activity level and independent variables (OKS, 6-MWT, TSK, BDI). The linear regression analysis was chosen to analyze the contribution of independent variables to physical activity level. Stepwise backward linear regression model was created to determine the most powerful predictors of physical activity level based on final regression analysis. The level of significance was set at $\mathrm{p}<0.05$.

\section{RESULTS}

Physical and demographic characteristics and mean OKS, 6-MWT, TSK, BDI and IPAQ-SF scores of patients with knee OA $(n=200)$ were summarized in Table 1a, b. There was no difference between sexes in terms of physical activity level $(p=0.23)$, fear of movement ( $>0.05)$, knee flexion range of motion (ROM) (right/left) $(p=0.27)$, or unilateral versus bilateral joint disease ( $p>0.05)$.

Spearman rank correlation coefficients were computed to identify correlates of components of OKS, 6-MWT, TSK, BDI and IPAQ-SF variables. IPAQ-SF was significantly correlated to OKS $(\mathrm{r}=-0.550), \quad 6-\mathrm{MWT} \quad(\mathrm{r}=-0.561)$, TSK $(\mathrm{r}=-0.693)$ and BDI $(r=-0.429)$ in patients with OA $(p<0.001)$ (Table 2).

Linear regression analysis revealed that OKS, 6-MWT, TSK and BDI outcomes were independently associated with IPAQ-SF and had the maximal significantly statistical contribution in predicting physical activity level in patients with knee OA ( $\left.\leq \leq 0.001 ; \mathrm{R}^{2}=0.621\right)$ (Table 3$)$.

\section{DISCUSSION}

The results of this study demonstrated that fear of movement, depression and functional performance are significant associates of 
self-reported physical activity level and can better predict the level of physical activity in patients with knee OA.

Physiotherapy and rehabilitation interventions aim to increase physical activity level in OA population through reducing OA-related disability. Physical activity also has the potential to improve muscle strength, reflex inhibition, proprioception, and ROM in the knee and decrease the risk of excess weight gain in OA patients. ${ }^{21}$ However, a critical finding of this study was that a majority of the subjects had low to moderate level of physical activity in spite of the recommended guidelines. The categorical classification of physical activity levels revealed that $6 \%$ were inactive, $78 \%$ were minimally active and $16 \%$ were very active. Similarly, in a study by Rosemann et al., ${ }^{22}$ physical activity levels of knee OA patients were found to be at moderate levels. The regression analysis in our study showed that the total OKS score, which assessed pain and functional status from the patient's perspective, was one of the important predictors of the level of physical activity. Likewise, in a study by Naal et al., ${ }^{23}$ OKS gave one of the best results for assessing the activity level. However, a study by Tonelli et al. ${ }^{24}$ on 208 knee OA patients demonstrated that physical activity levels may be similar, albeit with meaningful differences in pain severity.

Fear of movement has important clinical implications for individuals with OA including increased pain, physical disability, and psychological disability and recommendations regarding physical activity may vary based on main outcome measurements. ${ }^{25}$ There was no difference between the sexes in our study in terms of kinesophobia scores. Also, the study participants had moderate fear of movement. In addition, fear of movement was also related to the level of physical activity. Similarly, Scopaz et al. ${ }^{26}$ have shown that kinesophobia and anxiety affect physical activity levels in individuals with knee OA. In our study, the significant relationship between fear of movement and level of physical activity indicates that fear of movement may be an important marker for predicting the level of physical activity according to the regression analysis. Furthermore, Roaldsen et al. ${ }^{27}$ also reported that fear of moving may be used as a marker for the level of physical activity. Another study by
Filardo et al. ${ }^{28}$ on 200 patients with total knee arthroplasty showed that kinesophobia was also significantly associated with depression, particularly when avoiding physical activity.

The patients in our study showed minimal depressive symptomatology. The reason for a chronic low depression level might be a mean duration of illness of 8.5 years. In addition, there was a moderate relationship between depression and physical activity level. Similarly, in the regression analysis, the level of depression was a more significant indicator among the indicators of physical activity level of individuals with knee OA. A one-year follow-up study on 40 patients with knee OA demonstrated that depression levels decreased over time in the two, six, and 12-month evaluations from the beginning of treatment. ${ }^{29}$ In addition, a study of Summers et al. $^{30}$ on 65 individuals with OA showed a significant relationship between depression and physical activity parameters. Furthermore, Salaffi et al. ${ }^{31}$ also found a relationship between depression and physical activity level in a study of 61 females with knee OA.

Given the literature on the relationship between physical performance and physical activity, Dunlop et al. $^{32}$ have shown a perfect correlation between physical performance and physical activity level in individuals with knee $\mathrm{OA}$. In the regression analysis we conducted, a similar significant relationship was found between physical activity level and physical performance, suggesting that 6-MWT is an important predictor of the level of physical activity of individuals with knee OA. Likewise, in the literature, it has been suggested that 6-MWT is preferred in assessing the physical performance in knee OA. ${ }^{14}$

The cross-sectional and correlational design of this study is a limitation. While we can discuss the associations we detected, we cannot imply causality. Using self-reported measurements raises possible concerns over common method bias in the estimation of these relationships. Moreover, the lack of a validated fear of movement scale specific for OA limits the multidimensional assessment of fear of movement. Longitudinal analyses are needed to determine whether these results may be generalized to individuals living in other geographic regions and confirm the presented associations. 
In conclusion, physical activity levels are significantly related to OA symptoms and deserve more attention in both research and clinical practice. Results of the present study highlight the low functional status levels with high depression and kinesiophobia affecting physical activity levels to emphasize the need for assessment and innovative rehabilitation interventions in the population with knee OA. The factors that related to physical activity levels in our study were fear of movement, depression and functional performance. Physiotherapy interventions are needed to improve physical activity levels in daily life to modify risk or to implement early treatment strategies before the disease progresses and more costly solutions are needed.

\section{Declaration of conflicting interests}

The authors declared no conflicts of interest with respect to the authorship and/or publication of this article.

\section{Funding}

The authors received no financial support for the research and/or authorship of this article.

\section{REFERENCES}

1. Mesci E, Icagasioglu A, Mesci N, Turgut ST. Relation of physical activity level with quality of life, sleep and depression in patients with knee osteoarthritis.

North Clin Istanb. 2015;2:215-21.

2. Trans T, Aaboe J, Henriksen M, Christensen R, Bliddal $\mathrm{H}$, Lund $\mathrm{H}$. Effect of whole body vibration exercise on muscle strength and proprioception in females with knee osteoarthritis. Knee 2009;16:256-61.

3. Vahtrik D, Gapeyeva H, Aibast H, Ereline J, Kums T, Haviko T, et al. Quadriceps femoris muscle function prior and after total knee arthroplasty in women with knee osteoarthritis. Knee Surg Sports Traumatol Arthrosc 2012;20:2017-25.

4. Sezgin M, Erdal ME, Altintas ZM, Ankarali HC, Barlas IO, Turkmen E, et al. Lack of association polymorphisms of the IL1RN, IL1A, and IL1B genes with knee osteoarthritis in Turkish patients. Clin Invest Med 2007;30:86-92.

5. Wang SY, Olson-Kellogg B, Shamliyan TA, Choi JY, Ramakrishnan R, Kane RL. Physical therapy interventions for knee pain secondary to osteoarthritis: a systematic review. Ann Intern Med 2012;157:632-44.

6. Soyuer F, Senol V, Elmalı F. Huzurevinde kalan 65 yaş ve üstündeki bireylerin, fiziksel aktivite, denge ve mobilite fonksiyonları. Van Tip Dergisi: 2012;19:116-21.

7. Nacır B, Kudas S, Borman P, Can F, Erden Z, Kırdı $\mathrm{N}$ ve ark. Yaşlilarda fiziksel aktivite. In: Demirel $\mathrm{H}$, Kayhan H, Özmert EN, Doğan A, editörler. Türkiye Fiziksel Aktivite Rehberi. Ankara: Anıl Matbaa; 2014. s. 53-77.

8. Farr JN, Going SB, Lohman TG, Rankin L, Kasle S, Cornett $\mathrm{M}$, et al. Physical activity levels in patients with early knee osteoarthritis measured by accelerometry. Arthritis Rheum 2008;59:1229-36.

9. Song J, Semanik P, Sharma L, Chang RW, Hochberg MC, Mysiw WJ, et al. Assessing physical activity in persons with knee osteoarthritis using accelerometers: data from the osteoarthritis initiative. Arthritis Care Res (Hoboken) 2010;62:1724-32.

10. Committee IR. Guidelines for data processing and analysis of the International Physical Activity Questionnaire (IPAQ)-short and long forms. Available from: http://www ipaq ki se/scoring pdf. [Access: November 2005].

11. Terwee CB, Bouwmeester W, van Elsland SL, de Vet HC, Dekker J. Instruments to assess physical activity in patients with osteoarthritis of the hip or knee: a systematic review of measurement properties. Osteoarthritis Cartilage 2011;19:620-33.

12. Naal FD, Impellizzeri FM, Sieverding M, Loibl M, von Knoch F, Mannion AF, et al. The 12-item Oxford Knee Score: cross-cultural adaptation into German and assessment of its psychometric properties in patients with osteoarthritis of the knee. Osteoarthritis Cartilage 2009;17:49-52.

13. Tuğay BU, Tuğay N, Güney H, Kınıklı Gİ, Yüksel İ, Atilla B. Oxford Knee Score: cross-cultural adaptation and validation of the Turkish version in patients with osteoarthritis of the knee. Acta Orthop Traumatol Turc 2016;50:198-206.

14. Bennell K, Dobson F, Hinman R. Measures of physical performance assessments: Self-Paced Walk Test (SPWT), Stair Climb Test (SCT), Six-Minute Walk Test (6MWT), Chair Stand Test (CST), Timed Up \& Go (TUG), Sock Test, Lift and Carry Test (LCT), and Car Task. Arthritis Care Res (Hoboken) 2011;63 Suppl 11:S350-70.

15. Craig CL, Marshall AL, Sjöström M, Bauman AE, Booth ML, Ainsworth BE, et al. International physical activity questionnaire: 12-country reliability and validity. Med Sci Sports Exerc 2003;35:1381-95.

16. Saglam M, Arikan H, Savci S, Inal-Ince D, BosnakGuclu M, Karabulut E, et al. International physical activity questionnaire: reliability and validity of the Turkish version. Percept Mot Skills 2010;111:278-84.

17. Yllmaz T, Yakut Y, Uygur F, Uluğ N. Turkish version of the Tampa Scale for Kinesiophobia and its test-retest reliability. Physiother Rehabil 2011;22:44-9.

18. Vlaeyen JW, Kole-Snijders AM, Boeren RG, van Eek $\mathrm{H}$. Fear of movement/(re)injury in chronic low back pain and its relation to behavioral performance. Pain 1995;62:363-72. 
19. Beck AT, Steer RA, Carbin MG. Psychometric properties of the Beck Depression Inventory: twenty-five years of evaluation. Clin Psychol Rev 1988;8:77-100.

20. Hisli N. Beck Depresyon Envanterinin üniversite öğrencileri için geçerliği, güvenirliği. Psikoloji dergisi 1989;7:3-13.

21. Fransen M, Nairn L, Winstanley J, Lam P, Edmonds J. Physical activity for osteoarthritis management: a randomized controlled clinical trial evaluating hydrotherapy or Tai Chi classes. Arthritis Rheum 2007;57:407-14.

22. Rosemann T, Kuehlein T, Laux G, Szecsenyi J. Osteoarthritis of the knee and hip: a comparison of factors associated with physical activity. Clin Rheumatol 2007;26:1811-7.

23. Naal FD, Impellizzeri FM, Leunig M. Which is the best activity rating scale for patients undergoing total joint arthroplasty? Clin Orthop Relat Res 2009;467:958-65.

24. Tonelli SM, Rakel BA, Cooper NA, Angstom WL, Sluka KA. Women with knee osteoarthritis have more pain and poorer function than men, but similar physical activity prior to total knee replacement. Biol Sex Differ 2011;2:12.

25. Hodges PW, Smeets RJ. Interaction between pain, movement, and physical activity: short-term benefits, long-term consequences, and targets for treatment. Clin J Pain 2015;31:97-107.

26. Scopaz KA, Piva SR, Wisniewski S, Fitzgerald GK.
Relationships of fear, anxiety, and depression with physical function in patients with knee osteoarthritis. Arch Phys Med Rehabil 2009;90:1866-73.

27. Roaldsen KS, Elfving B, Stanghelle JK, Talme T, Mattsson E. Fear-avoidance beliefs and pain as predictors for low physical activity in patients with leg ulcer. Physiother Res Int 2009;14:167-80.

28. Filardo G, Merli G, Roffi A, Marcacci T, Berti Ceroni F, Raboni D, et al. Kinesiophobia and depression affect total knee arthroplasty outcome in a multivariate analysis of psychological and physical factors on 200 patients. Knee Surg Sports Traumatol Arthrosc 2017;25:3417-23.

29. Calfas KJ, Kaplan RM, Ingram RE. One-year evaluation of cognitive-behavioral intervention in osteoarthritis. Arthritis Care Res 1992;5:202-9.

30. Summers MN, Haley WE, Reveille JD, Alarcón GS. Radiographic assessment and psychologic variables as predictors of pain and functional impairment in osteoarthritis of the knee or hip. Arthritis Rheum 1988;31:204-9.

31. Salaffi F, Cavalieri F, Nolli M, Ferraccioli G. Analysis of disability in knee osteoarthritis. Relationship with age and psychological variables but not with radiographic score. J Rheumatol 1991;18:1581-6.

32. Dunlop DD, Song J, Semanik PA, Sharma L, Chang RW. Physical activity levels and functional performance in the osteoarthritis initiative: a graded relationship. Arthritis Rheum 2011;63:127-36. 